\title{
Evolution OF THE CEPHALOTUS PITCHER
}

\section{JOHN BRITTNACHER・Ashland• Oregon•USA•john@carnivorousplants.org}

Keywords: Cephalotus follicularis, leaf development, evolution, carnivory.

Abstract: Cephalotus follicularis (Oxalidales) is a carnivorous plant native to coastal southwest Australia with pitchers that primarily trap ants. The plant also produces non-trapping foliar leaves and occasional intermediate leaves. Close observation of the intermediate leaves plus an understanding of leaf development in angiosperms shows that the pitchers appear to be constructed from five leaflet-equivalent developmental domains that are not separately visible in the pitcher leaf primordia but do map to specific locations. The pitcher development patterns are similar to those of Oxalis leaves. Simple developmental shifts can explain the evolution of the pitcher. The pitcher body appears to have evolved from the three leaflets typical of most Oxalis species and the lid from two leaflets that arise above the adaxial face of the petiole in a way similar to the adaxial leaflet of Oxalis tetraphylla. However, since the lineage consisting only of Cephalotus today is 80 million years old, when and how it became carnivorous and developed pitchers remains speculative.

\section{Introduction}

Cephalotus is in the monotypic family Cephalotaceae which is part of a basal lineage within the angiosperm order Oxalidales. This order diverged from the other flowering plants approximately 100 million years ago (Li et al. 2019). As defined currently, the Oxalidales contain about 1900 species in seven families, including the well-known wood sorrel family Oxalidaceae (Stevens 2017a). Those families most closely related to Cephalotus, albeit distantly, include Brunelliaceae, Connaraceae, Cunoniaceae, and Elaeocarpaceae (Cross et al. 2019; Stevens 2017a). Based on DNA evidence, Cephalotus diverged from its living relatives around 80 million years ago (Heibl \& Renner 2012; Li et al. 2019). As the various lineages within Oxalidales have all diverged substantially since that time, it is difficult to even guess what their common ancestor looked like. The majority of Cephalotus' nearest relatives are large rainforest trees.

Cephalotus has two basic kinds of leaves, pitchers that primarily trap ants but have limited photosynthesis utility (Back Cover) and "foliage" leaves (Fig. 1-2) which provide for photosynthesis especially under low light conditions and during seasons with fewer ants (Nunn 2014; Cross et al. 2019). One would think that with 200 years of Cephalotus being in cultivation and being studied, there would be a consensus on the developmental biology of Cephalotus leaves. There isn't. John Macfarlane's 1889 introduction to his discussion of Cephalotus in a paper about carnivorous plant pitchers (Macfarlane 1889) starts out:

The pitchers of this genus [Cephalotus] appear to differ in every respect from those just passed under review [Nepenthes, Heliamphora, Sarracenia, Darlingtonia], so that no comparison of them can be made. As Dickson clearly showed, the pitcher is a laminar involution, while the lid is a flap of the lamina growing forward over it. Like many other Australian plants therefore it seems to represent one of a chain of forms otherwise lost to us. 
Alexander Dickson studied what he considered developmentally teratogenic (abnormal) pitchers (Dickson 1883). At that time Cephalotus plants were so precious to the Edinburgh Botanic Garden, he dared not to damage them so all he could do was look. Dickson's conclusions about how Cephalotus pitchers are constructed, with some additions, have remained the dogma to this day:

The conclusions to which I have been led may thus briefly be stated:

1 st. That the pitcher results from a calceolate pouching of the leaf-blade from the upper surface.

$2 \mathrm{~d}$. That the apex of the leaf is on the far side of the pitcher-orifice from the main axis and from the lid, and is probably represented by the tip of the middle dorsal wing.

$3 \mathrm{~d}$. That the pitcher-lid represents an outgrowth or excrescence from the upper leaf-surface.

The main issues of discussion today relate to "calceolate pouching" and the pitcher lid being an "excrescence". An example of calceolate pouching is the pouched petal of lady slipper orchid flowers. Calceolate pouching would imply the pitcher is formed by deformation of a leaf element rather than leaf elements merging to form a pitcher. If the pitcher lid of Cephalotus is an excrescence, it would mean the lid is essentially an outgrowth of the petiole and not a modified leaflet. Intermediate leaves between pitchers and foliage display pouching as well as hints of other trap elements (Fig. 1). But what do the intermediate leaves tell us about how pitchers and foliage leaves are constructed and how Cephalotus pitchers evolved? Are the traps essentially a pouched leaf or is it more complicated?

\section{Materials and Methods}

This study was done while propagating Cephalotus plants by stem cuttings in the fall. Owing to space constraints, plants were shifted between an indoor terrarium that experienced temperatures of $19^{\circ} \mathrm{C}$ to $26^{\circ} \mathrm{C}$ with a 14 -hour constant photoperiod and a garage grow area with water trays and humidity domes at temperatures of $10^{\circ} \mathrm{C}$ to $20^{\circ} \mathrm{C}$ and a natural and artificial light period based on local sunrise and sunset. Indoors, the range of temperatures were experienced diurnally, while in the garage, temperatures were more constant diurnally but shifted higher or lower every few weeks in accordance to the outdoor temperatures. Under the indoor conditions, mature plants sparsely produce foliage leaves and have not bloomed over a 13-year period. In the garage, the plants produce foliage leaves during the winter and bloom in
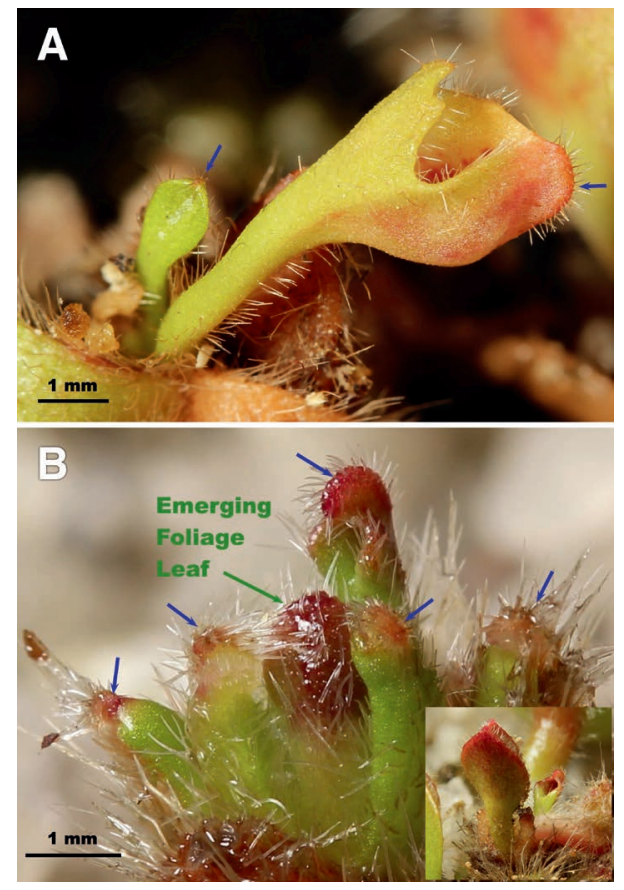

Figure 1: Cephalotus intermediate leaves. Blue arrows indicate protrusions that relate to the keel segment on the front of typical pitchers. The $\mathbf{B}$ inset was taken 40 days after the main image showing mature foliage leaves. 
the spring. The Oxalis tetraphylla used were standard retail plants purchased locally; sold under the name Oxalis deppei 'Iron Cross'. Most of the photos were taken using a Canon DSLR camera and $60 \mathrm{~mm}$ macro lens with some photos also using an extension tube. The camera was controlled from a computer by Helicon Remote (www.heliconsoft.com). Multiple images in different focal planes were processed by Helicon Focus to produce what are called focus stacked images. A photo of a 1 $\mathrm{mm}$ grid was taken at the same settings and distance and processed with the corresponding set of images to provide a separate image for measurements of scale. Some scale measurements are from direct measurement of the subject.

\section{Angiosperm leaf development}

There are essentially two stages in angiosperm leaf development (Champagne et al. 2007; Efroni et al. 2010). The first stage consists of a leaf primordium arising near a stem apical meristem (see Fig. 2 for an explanation of terms). This would be visible as a very small mound of cells. The stem apical meristem provides the primary axis of orientation for local development using hormone gradients (Fukushima \& Hasbe 2014; Yamaguchi et al. 2012). The leaf primordium consists of undifferentiated cells also referred to as indeterminate cells. The leaf primordium also sets up a hormone gradient emanating from the far distal side of the primordium (Waites \& Hudson 1995). Using these gradients and cell-tocell communication, the indeterminate cells orient and divide in ways that place cells in a structure that will be used in the second stage. This first stage can have substages if the ultimate leaf is complicated (Bharathan et al. 2002). The end result is usually a very small, very vague version of the mature leaf.

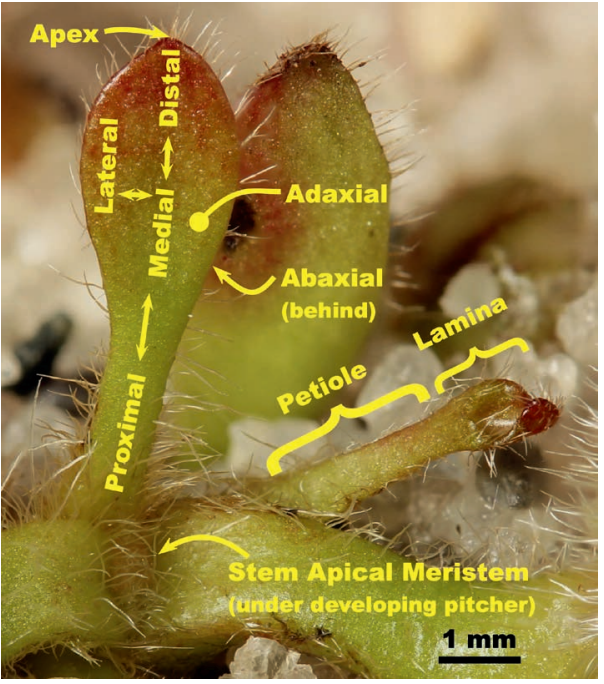

Figure 2: Botanical terms used to describe plant parts. The adaxial face refers to the side of the leaf on the stem apical meristem (SAM) side, abaxial refers to the side facing away from the SAM. Petiole refers to the proximal, stem-like part of a leaf. Lamina refers to the leaf blade or leaflets at the distal end of a leaf.

The leaf development second stage is when the undifferentiated indeterminate cells receive a hormonal signal telling them to differentiate (Efroni et al. 2010). The determinate cells may not be fully mature, but their fate is set. The determinate cells communicate among themselves, grow larger and specialize to become the structure of the new leaf. Not all the cells in the developing leaf need to enter stage two at the same time, so again, things can get complicated to make complicated leaves. How plant cells communicate to produce their structures is an emerging field so I will generally use "signaling" here to indicate any sort of communications that could involve hormones like auxin or other chemicals such as small RNAs.

\section{Peltate leaves}

Oxalis species such as Oxalis tetraphylla (Fig. 3) and Tropaeolum majus (nasturtium) provide good examples to help understand Cephalotus pitcher development. Not all Oxalis species show the characteristics described here. There are important parallels between O. tetraphylla 
and Cephalotus leaf development. The most obvious parallels are both genera have peltate petiole attachment to the leaf lamina and $O$. tetraphylla leaves and Cephalotus pitchers develop with leaf tips pointed back at the base of the leaf.

Hagemann and Gleissberg (1996) have superb images showing leaves at the leaf primordium stage including the peltate leaf of Tropaeolum majus. Nasturtium is the poster child of peltate leaves and the authors show how peltation occurs in that species. The leaf primordium starts out with the distal side palmate and containing five joined leaflet primordia looking like a maple leaf. As the petiole grows and becomes round, two more leaflet primordia appear on the proximal side producing a lopsided, seven-point crown. Hagemann and Gleissberg describe the appearance of the new leaflet primordia as growth from around the leaf primordium forming a new ridge on the proximal side for the new

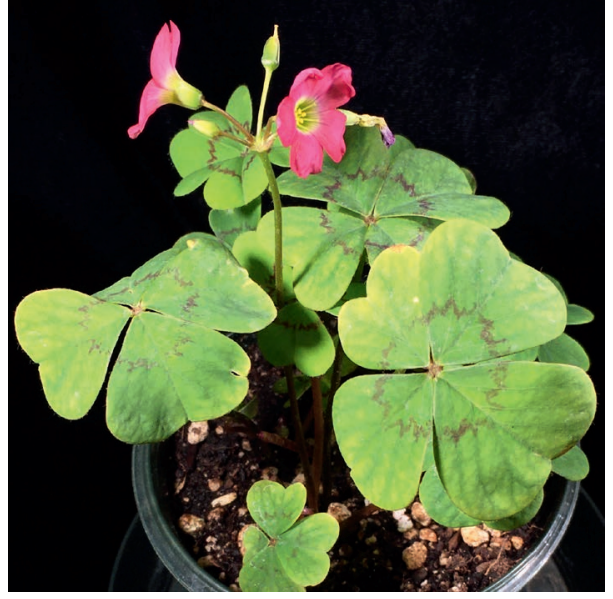

Figure 3: Oxalis tetraphylla plants. Notice the strong midrib on each leaflet. The leaflets only open in bright light. Under dim light and darkness, the leaflets fold at the midrib and point down by hinging at the leaflet base. primordia. Fukushima and Hasbe (2014) refer to this ridge as the "cross zone". The cross zone effectively crosses the proximal, inner/adaxial part of the future petiole. It is what changes a sided palmate leaf to a peltate leaf.

It is unfortunate the use of the words "adaxial" and "abaxial" can make the discussion of leaf development confusing. I will be redundant to help make the discussion clear. Adaxial and abaxial can be used to indicate direction or orientation as in the adaxial/abaxial development axis. The words can also specify the faces of leaf elements corresponding to that axis. The adaxial face of a leaf element is usually the inner side facing the apical meristem or the upper sun-facing side. The abaxial face is the outer side facing away from the apical meristem or the lower shaded side. In most leaf types, the assignment of adaxial or abaxial is quite straightforward. In peltate and pitcher-like leaves, assignment of leaf faces can be difficult because it may not be clear how to assign leaf structures that arise from the cells in the cross zone. In describing leaf development, it is critical to be able to keep track of structural orientation.

Adaxial/abaxial confusion can be seen in O. tetraphylla. O. tetraphylla, as the name implies, has four leaflets while most Oxalis species have three leaflets. The fourth leaflet is above the inner/ adaxial side of the petiole. The adaxial part of the petiole of $O$. tetraphylla can be traced explicitly because it starts out flat and shifts to rounded (Fig. 4A-C). Where the flat petiole margins disappear, the petiole becomes a rounded " $\mathrm{D}$ "-shape with the flattened part being the inner/adaxial face. This flattened area can be traced all the way to the leaflets in $O$. tetraphylla leaves with three leaflets as in Figure 4A. In the typical four leaflet leaves, the petiole is rounder and it is difficult to trace the flat area the last few $\mathrm{cm}$ to the leaflets. The critical observation is that at no point along the petiole do the margins of the flat area come together as would be expected if the inner/adaxial face associated with this flat area was pinched off. The petiole just becomes round. In Cephalotus the petiole is definitely "D"-shaped (Fig. 4D-E) until right before it attaches to the pitcher. The veins in the proximal flattened part of the Oxalis leaf form an arc as is typical in non-peltate leaves (Fig. 4C). In both species, the petiole veins are in a circle in the rounded part (Fig. 4B,D-E). 

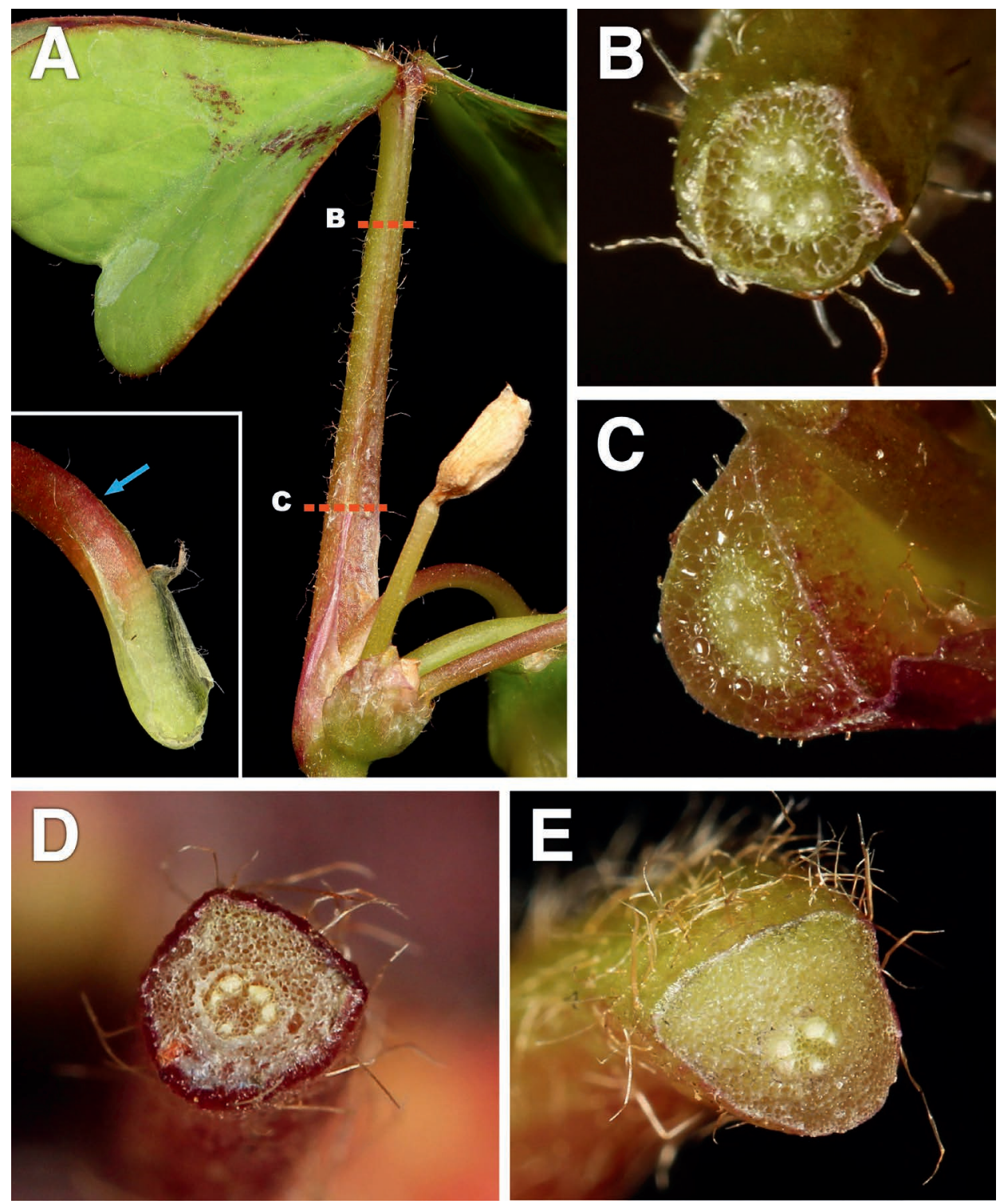

Figure 4: The main image in $\mathbf{A}$ is a three-leaflet leaf of Oxalis tetraphylla from the top of a flower scape. The orange dotted lines are where cross sections were taken for images $\mathbf{B}-\mathbf{C}$. The inset in $\mathbf{A}$ is a four-leaflet leaf petiole from a flower scape. The blue arrow in the inset is where the leaf margins fade. D-E show cross sections of Cephalotus pitcher petioles.

Leaf margin signaling is not well understood (Fukushima \& Hasbe 2014), but I believe the circle of leaf veins occurs because of the lack of leaf-margin signaling rather than a loss of adaxial/ abaxial signaling. This is because in peltate leaves, the leaf components maintain an adaxial/abaxial orientation throughout development. This is important because it means there is no special set of 
developmental rules for peltate leaves. Peltation simply results from one end of a continuous range of variation in the balance of adaxial/abaxial signaling and leaf-margin signaling. In peltate petioles the adaxial/abaxial balance is somewhat shifted adaxially and the leaf-margin signaling is suppressed. If leaf-margin signaling was not disabled in peltate leaves where the petiole terminates at the base of the leaf lamina, the leaf lamina would open up and thus not be peltate.

\section{Oxalis leaf development}

The shape of the leaf primordium reflects the ultimate structure of the leaf. Typical Oxalis leaves have three leaflets. Based on other genera with peltate leaves where there are published images, the leaf primordia of an Oxalis with three leaflets should look like a crown with three points. O. tetraphylla, with its four leaflets, should look like a crown with four equally spaced points. The fourth point or leaflet primordia would be on the inner/adaxial side of leaf primordia proximal to the stem apical meristem in the cross zone.

As the leaf of O. tetraphylla develops, all of the leaflets develop at the same time (see Fig. S3 in Bharathan et al. 2002 or Champagne et al. 2007 for images of a different Oxalis species), but the petiole grows asymmetrically to produce an almost $180^{\circ}$ bend in the inner/adaxial direction pointing the leaflet tips toward the apical meristem (Fig. 5). At this stage in O. tetraphylla, the major
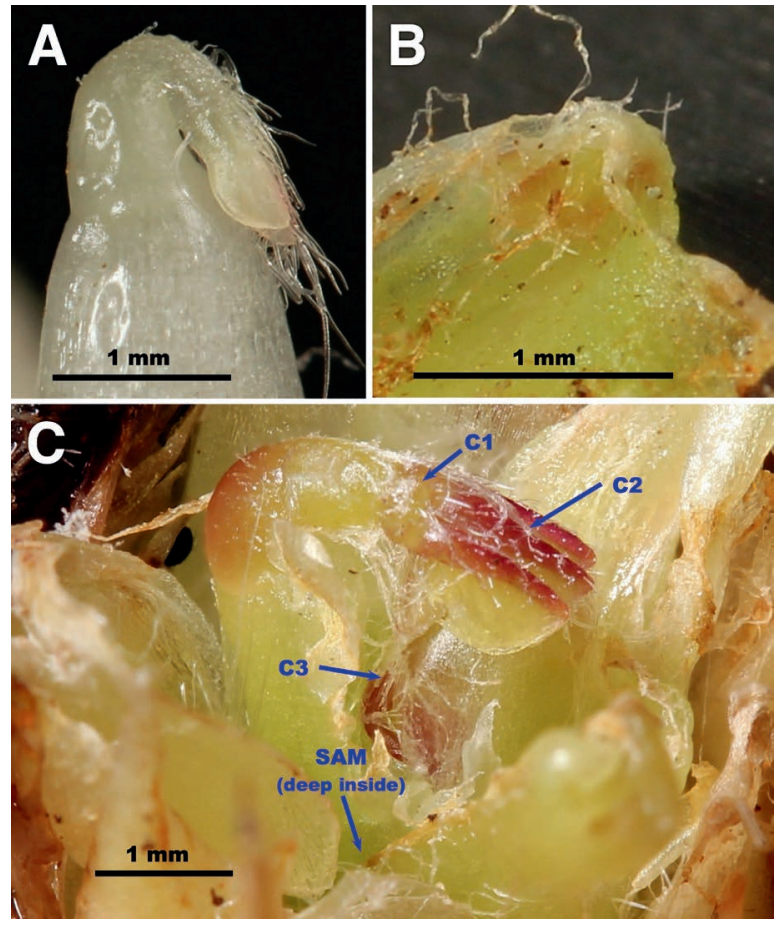

Figure 5: Developing leaves of Oxalis tetraphylla. A shows the first leaf produced by a bulbil. $\mathbf{B}$ is a developing leaf dissected from a bulb. C shows two leaves excavated from a bulb. C1 will become the hinging leaflet base; $\mathbf{C 2}$ are the leaflets; $\mathbf{C} \mathbf{3}$ is a second leaf. 
leaflet vein of all three outer/abaxial leaflets face away from the arched petiole and the leaflet leaf segments are folded toward the petiole. The fourth leaflet is attached to the inner/adaxial region of the petiole proximal to the arch of the petiole. The major leaflet vein is on the side under the petiole arch with the leaflet segments folded away from the petiole among the outer/abaxial leaflets. When Oxalis species with bulbs are buried, having the petiole bend and leaflet tips pointed toward the apical meristem allows each leaf to push up through the same hole to the soil surface. This helps keep the leaflets from being damaged during their journey to the surface. When the leaves reach their ultimate height, the cells on the inner/adaxial side of the petiole grow to orient the sun side of the leaflets upward.

\section{Cephalotus pitcher development}

In plants, one cannot generally use "ontogeny recapitulates phylogeny" to help understand the evolution of a species. All angiosperms go through the same basic developmental steps and there are no bizarre relics of past designs like we find in animals. In plants, that means studying relatives instead. However, the comparison to Oxalis does not hold for the initial leaf primordium. In fact, the leaf primordium of Cephalotus looks more like the one for Sarracenia purpurea (Fukushima et al. 2015), except in Sarracenia the leaf primordium wraps the apical meristem rather than being off to the side as in Oxalis and Cephalotus. Figure 6A is a drawing based on a scanning electron microscope image from Froebe and Baur (1988) where I have indicated where cells are staged for later development. This arrangement is drastically different from "normal" flat leaves.

In Cephalotus, the equivalent of the Oxalis leaflet most distal from the apical meristem develops first. This developmental domain arches over the top of the primordium in Cephalotus but does not in Oxalis. It is typical for the primordium to go from indeterminate to determinate in a wave from the top/distal point down (Yamaguchi et al. 2012). That is what happens here. What is first seen in
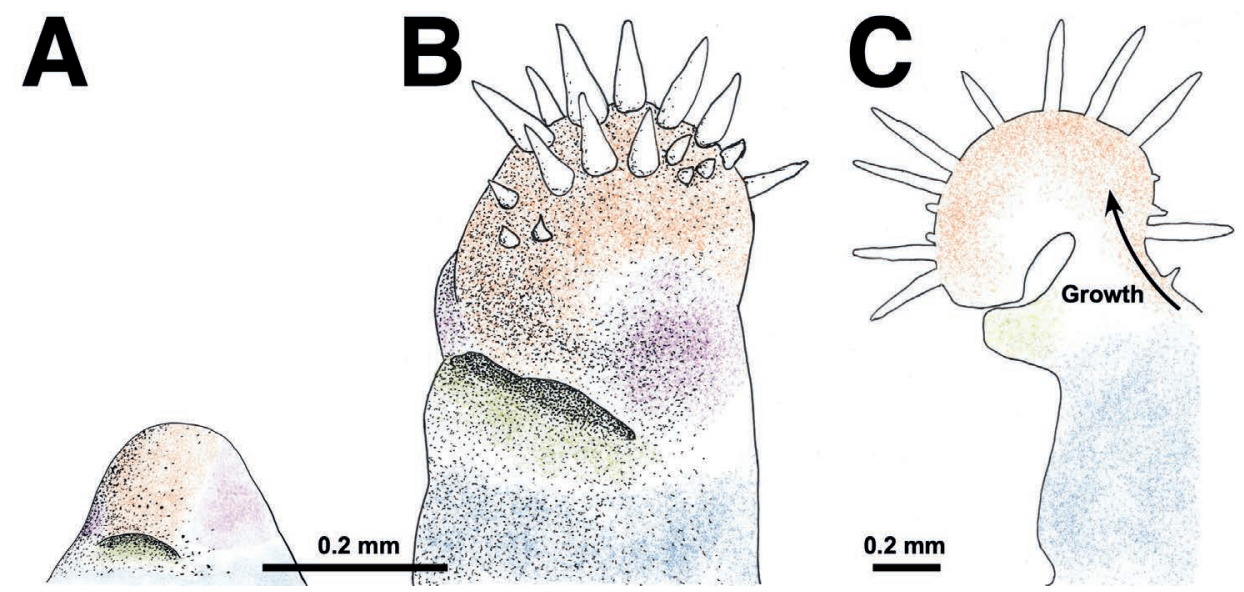

Figure 6: Drawings showing the growth of Cephalotus pitcher primordia with different shading colors representing approximate locations of development segments. The drawings $\mathbf{A}-\mathbf{B}$ are based on scanning electron microscope images and $\mathbf{C}$ on a light microscope longitudinal section image in Froebe and Baur (1988). Orange shading corresponds to the front keel developmental domain, violet to the side wings, green to the lid, and blue to the petiole. 
the developing primordium is the ridging and hairs of the front keel of the pitcher (Fig. 6B which is based on Froebe and Baur 1988 Figs. 9-12). The lateral wing leaflet domains expand as necessary to accommodate the growth of the front keel but do not appear to differentiate. Nothing much happens to the proximal leaflet domains destined to be the lid at this stage. As the keel grows, it opens up the inside of the leaf, forming a pitcher (Fig. 6C based on Froebe and Baur 1988 Fig. 15).

The pitcher continues to develop in a looping manner similar to O. tetraphylla leaves with Cephalotus having an approximately 90-degree bend near the distal end of the petiole. Typically, when the developing pitcher is about $1 \mathrm{~mm}$ long, the petiole is very short and the pitcher covers the apical meristem with the keel pointing up (Fig. 2). At a pitcher length of $2 \mathrm{~mm}$ the petiole is longer and the lateral wings have formed as well as the lid, but the back of the pitcher has not formed (Fig. 7A). Note how the keel, lateral wings and lid radiate directly from the petiole attachment in a way reminiscent of Oxalis. When the pitcher back finally grows, it straightens the curved front keel with
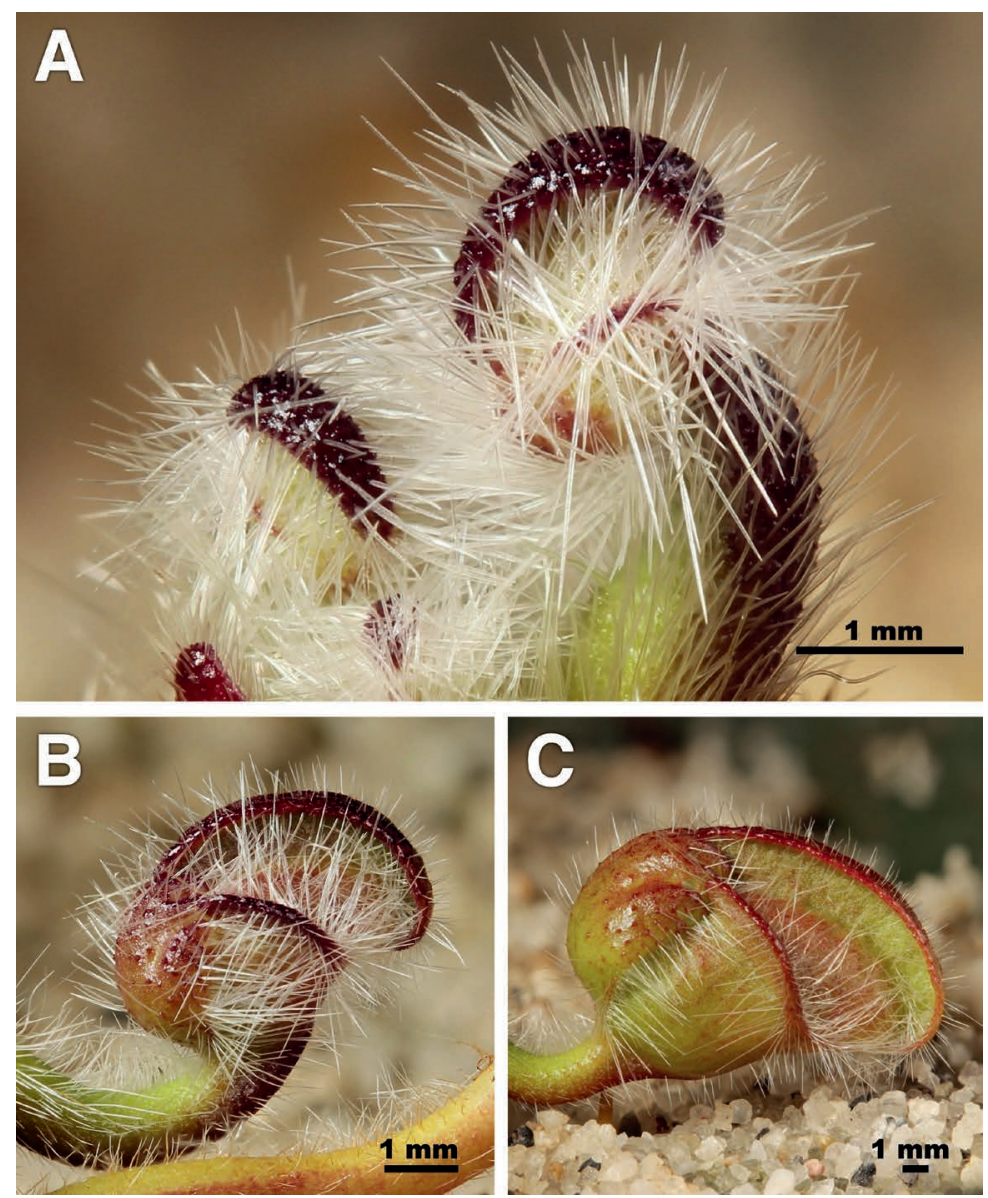

Figure 7: Developing Cephalotus pitcher. Notice in $\mathbf{A}$ the petiole makes a $90^{\circ}$ bend and how the bases of the keel, side wings, and lid come together at the petiole. In $\mathbf{B}-\mathbf{C}$ the elements are separated as the pitcher back expands. 


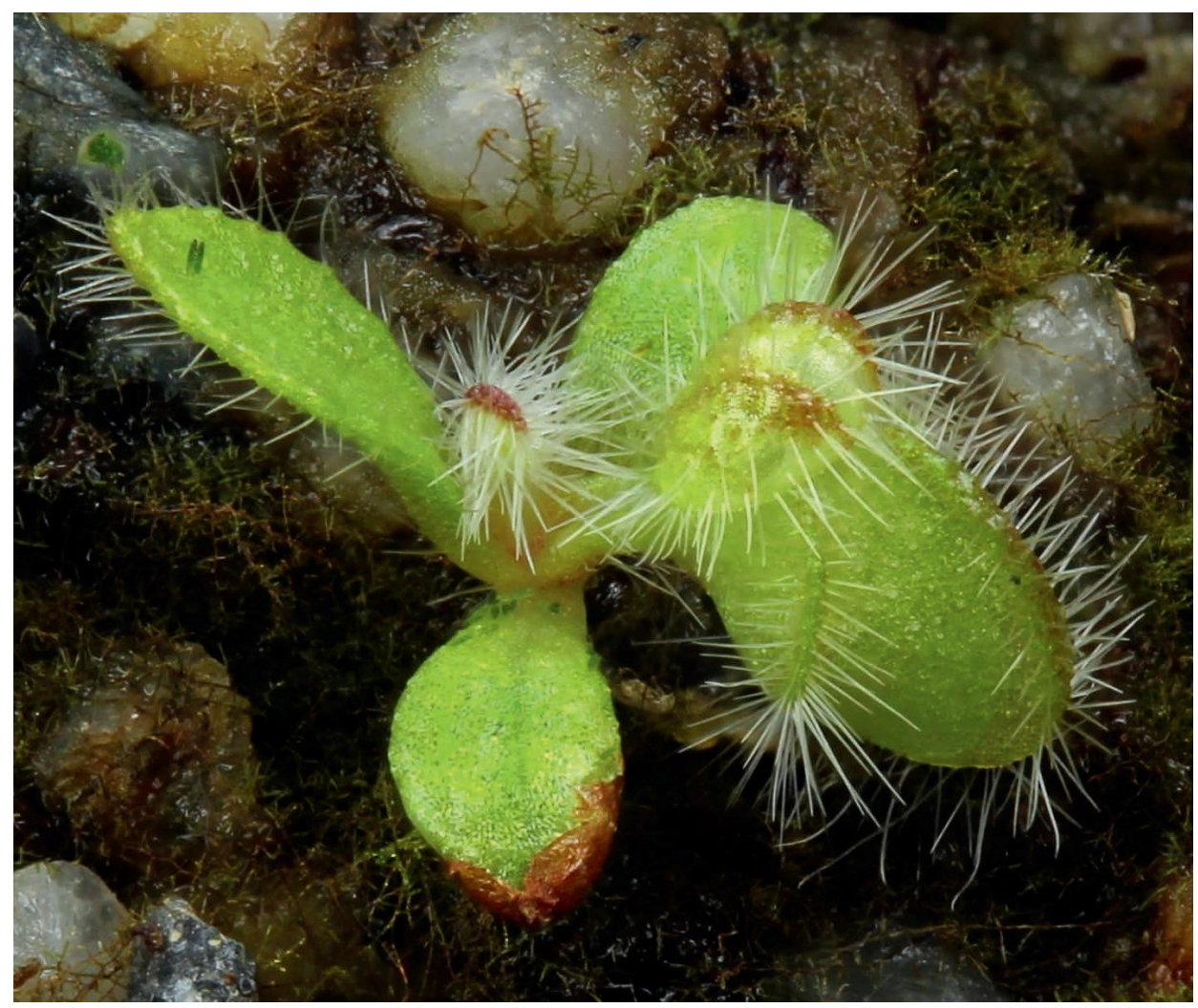

Figure 8: Cephalotus seedling. The first true leaf is a foliage leaf. The juvenile pitchers lack some of the intricacies of adult pitchers.

the result that the final form of the pitcher is determined. It is in a position essentially laying on its back with the apex of the keel pointing back at the apical meristem (Fig. 7C). The petiole continues to grow to push the pitcher away from the stem apical meristem. In compact plants with many pitchers, the bottom of the pitcher acts as a battering ram to get the new pitcher past older pitchers and into the light. When the pitcher is in place, the cells on the inner/adaxial side of the petiole where it attaches to the pitcher grow to flip the pitcher upright and finish the expansion of the back. The juvenile and adult pitchers display all these features although the juvenile pitchers are somewhat simplified (Fig. 8), likely owing to different prey species.

\section{Cephalotus foliar and intermediate leaves}

Based on morphological studies, Cephalotus foliar leaves are expanded petioles (Arber 1941; Lloyd 1942; Franck 1976) although these and other authors may not put it so bluntly or they use the word "petiolate". DeGreef (1990) suggested the foliage leaves are "inhomogeneous, teratological structures" because the base, or "petiole", of the foliar leaves show typical peltate circular arrangement of veins which then flare out in the upper widened flat "lamina" part of the leaf. If circular arrangement of the veins results from a loss of leaf margin signaling, then all it would take is the leaf margin signaling to be turned on to widen the leaf and flare out the veins. Otherwise 
there is little remarkable about the foliage leaves other than they are quite simple and both faces are similar. Eucalyptus is a good example of a bifacial leaf where both faces can be essentially the same in order to allow maximal photosynthesis from light penetrating both sides (Evans \& Vogelmann 2006).

Cephalotus has a complete range of intermediate leaves that can appear in the fall and winter. The types of intermediate leaves include foliar leaves that are dished or pouched with just a hint of the keel on the outer/abaxial side or foliar leaves with one knobby spot of red at the apex containing a tuft of long hairs, to leaves that appear to be almost functional incompletely differentiated pitchers. Figure 9A-B show a dished foliar leaf with a small pitcher keel on the outer/abaxial side. It appears the presence of the keel induces the leaf to dish. Figure 9C-E show the development over time of a sided palmate intermediate pitcher after the petiole has grown to its ultimate length. Initially there are four hair tufts and a small front keel. Notice how the keel initially covers the center top of the petiole and later bends up. This leaf has some leaf-margin signaling which opens up the space between the two tufts corresponding to what could have been a lid. As the leaf matures, the keel and lid components become more prominent although the lid components show no hint of producing a lid at maturity. The five leaflet components can be seen clearly in the mature leaves in Figure 10A-B. Figure 10D-F show pitcher-like leaves with an entire lid. They have different degrees of "back" development, which in these intermediate pitchers is the bottom. Figures 11-12 show more intermediate leaves with various developmental patterns. Figure 12A is most interesting because it is a sided palmate intermediate leaf where the domains I have identified as "lid" form clear patches like typical pitcher lids.

In the intermediate leaves seen in this study, the front keel is the developmentally dominant segment and it does tend to bend the way that segment does in typical pitchers, but the petiole does not bend to project the keel forward. Instead the keel projects down. In the intermediate leaves with definite lids, the lid projects distally rather than adaxially toward the flat side of the petiole (Figs. 1A, 10D-F, 11E-F). Again, this is because the petiole does not bend as seen in Figure 7A. Intermediate pitchers are built straight up and out instead of on their backs and then flipped up. It appears that for each intermediate leaf, the petiole and lamina are each running a different mix of pitcher and foliar leaf development programs. The palmate intermediate leaves have more leaf margin signaling with the lamina tending toward a foliar leaf. The simplified pitchers lack the definite leaf margin signaling that would pull the pitchers apart but also lack the complex developmental patterns to produce a typical pitcher that would work to catch ants.

Cephalotus can also produce miniature flower scapes. Figure $9 \mathrm{~F}$ shows a $4.5 \mathrm{~mm}$ long petiole with a $5 \mathrm{~mm}$ long flower scape containing what appear to be tiny flower buds at the apex. Cross et al. (2019) surmise that intermediate leaves, which also apply to this case of miniature scapes, occur as a result of stress during changing seasons. Flower scapes appear in the early spring. Cephalotus likely has a temperature-dependent development control which could be used to study general questions in plant developmental biology in a similar way as a temperature sensitive mutant in Antirrhinum majus (snapdragon) that was used by Waites and Hudson (1995). To do such studies would require a determination of the parameters that trigger intermediate leaves.

What is most important about intermediate leaves from an evolutionary standpoint is we can identify how leaf construction is compartmentalized in a leaf where we cannot actually see individual leaflet primordia. We see five developmental domains in intermediate leaves. Each domain is likely equivalent to an ancestral leaflet. We cannot see leaflet primordia in the images of Froebe and Baur (1988) because they studied normal pitcher primordia which have the leaflet primordia fused. The primordia of intermediate leaves probably have interesting details. 

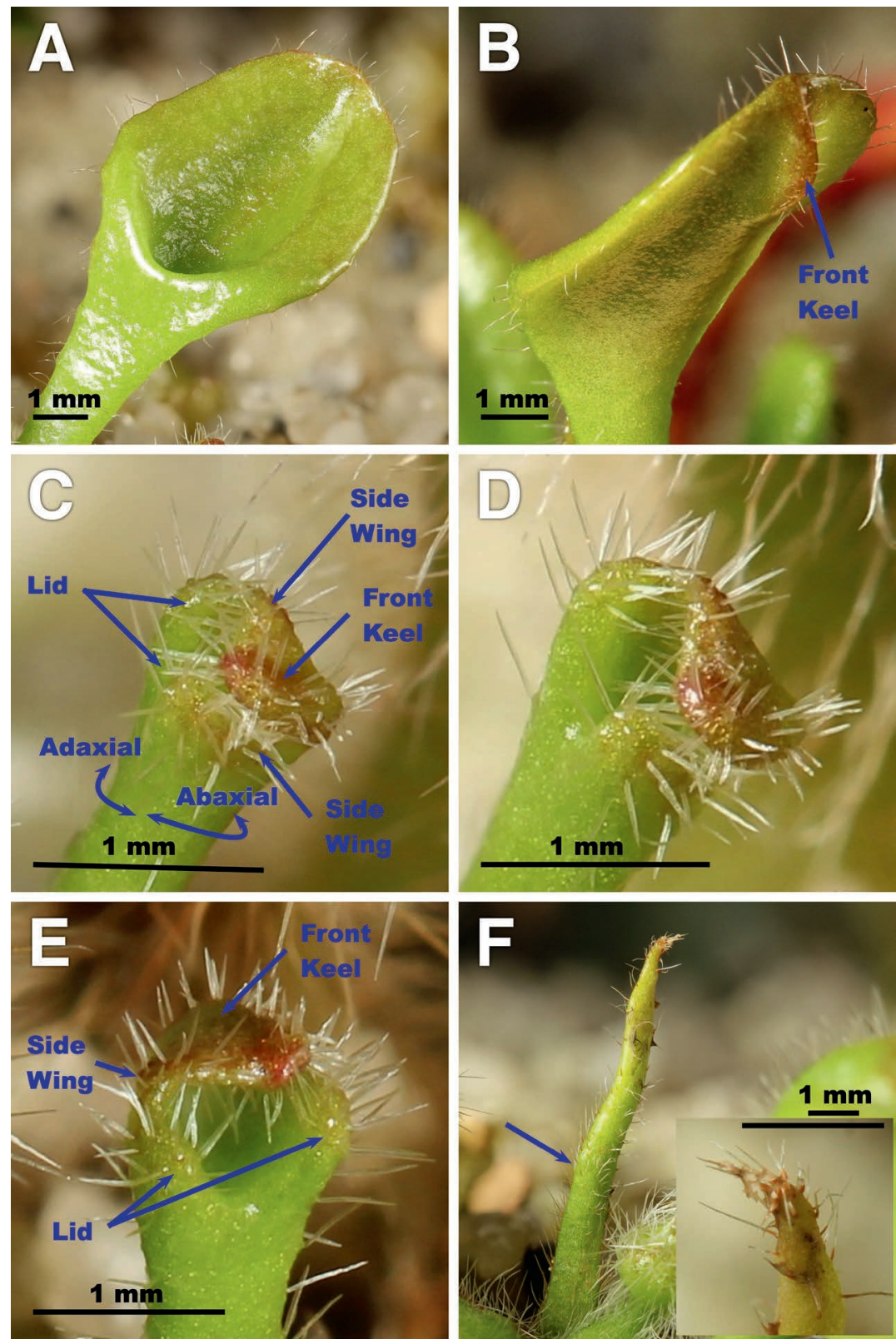

Figure 9: A-B show a pouched foliar leaf with a keel on the abaxial side (arrow). C-E show a developing intermediate leaf. Of the five leaflet primordia, only the keel makes a recognizable feature. The leaf developed a small dead area which resulted in the keel skewing to the side as it matured. $\mathbf{F}$ is a needle-shaped leaf that appears to be a miniature flower scape. From the apical meristem to the arrow, the scape is " $D$ " shaped in cross section like a petiole. At the arrow it transitions to nearly round. The apex appears to have tiny flower buds. 

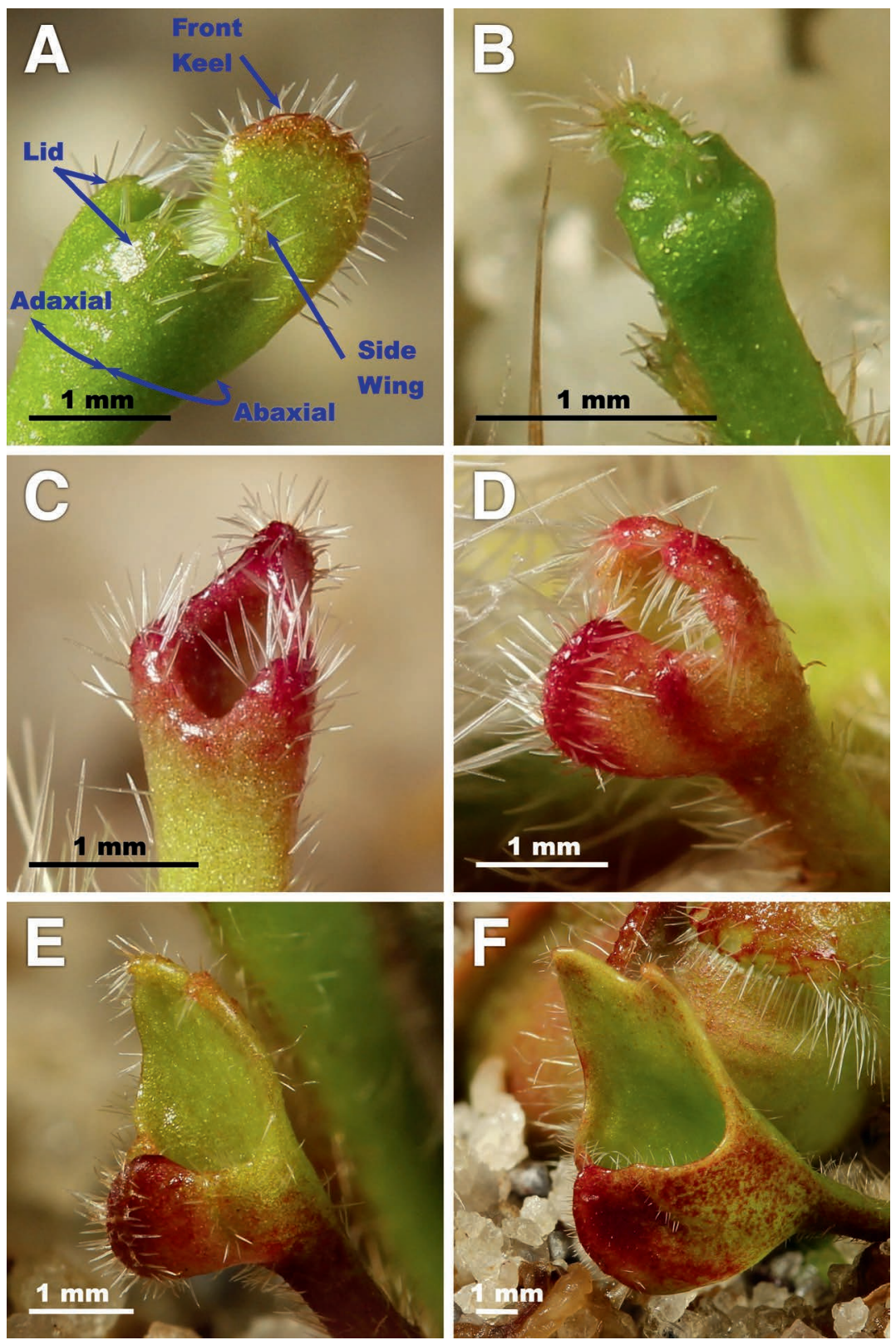

Figure 10: Mature Cephalotus intermediate leaves. A-B show the leaflet developmental domains. B did not develop beyond the point shown. $\mathbf{C}$ is a sided palmate intermediate leaf. D-F are peltate intermediate pitcher leaves. D has all the developmental domains terminating at the petiole. E-F have an expansion along the bottom that is similar to what is seen in typical pitcher backs. 

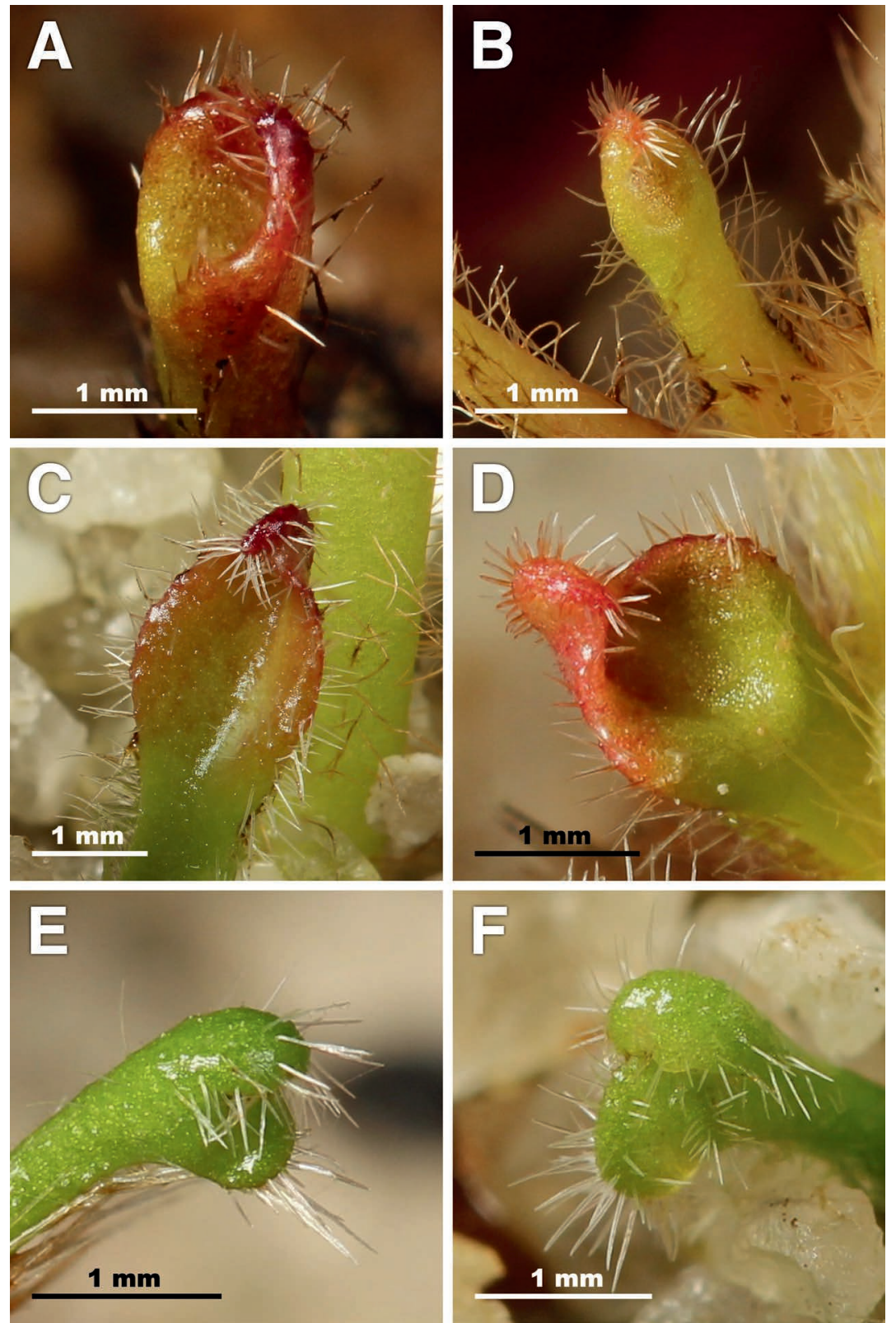

Figure 11: Additional examples of Cephalotus intermediate pitchers. A-D show various degrees of foliar leaf influence. E-F show how without the $90^{\circ}$ adaxial bend in the petiole, the pitcher-like intermediate leaves develop in an upright position with the keel arching down. 

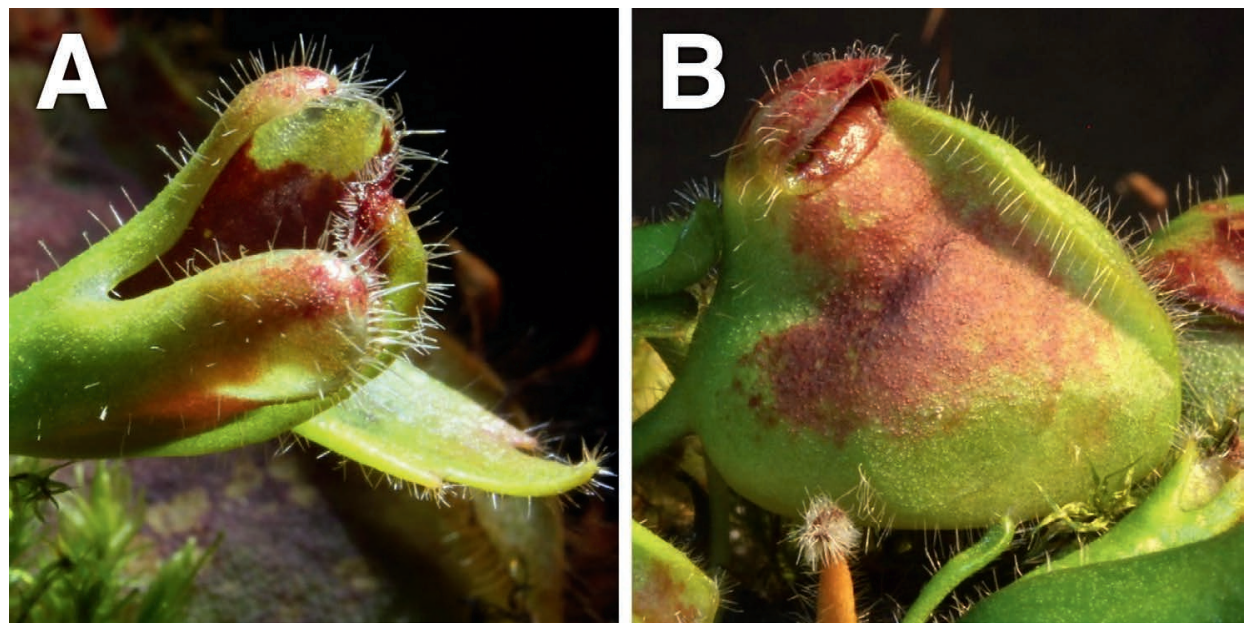

Figure 12: In this this study, I did not observe any palmate intermediate leaves showing characteristics of a lid in the inner/adaxial developmental domains I refer to as "lids". Robert Gibson kindly provided image A that shows clear areas as seen in typical Cephalotus pitchers. Note the unusual intermediate leaf in the background as well. Gibson also provided the image B showing a large intermediate pitcher. Clayton (2013) also observed large intermediate pitchers. Note in this case the side wings are missing or displaced to the bottom of the pitcher. The mouth teeth are present but obscured by nectar. The usual trace of hairs that separate the side wing domain from the lid domain is present.

\section{Cephalotus leaf evolution}

It is easy to say that the pitchers of Cephalotus follicularis evolved from a compound leaf. But it is not so easy to understand exactly how that happened. How does a plant lineage reliant on photosynthesis in compound leaves evolve to be dependent on nutrients from captured prey in pitchers? Every single step the plants take in that process must make sense for their current situation. The plants that have taken a small step toward carnivory must have a higher reproductive value than the plants that did not and thus be represented in greater proportion in the population of the species going forward. There would be no map or plan for the future, no sacrifice now for a reward later, just what works in the present. A botanist looking at the plants in the very distant past would have no clue that in a few million years the descendants would be carnivores. Similarly, looking backward today, the plants can offer us clues to how they became carnivorous, but there will always be some level of uncertainty. We do have one advantage in that carnivorous plants are not inventing new biology.

John DeGreef (1990) summarized in CPN the thoughts on Cephalotus evolution prior to 1990. At that time, we did not know Cephalotus has a separate lineage going back about 80 million years, which plant order it is in, and certain details of basic leaf development. Now we know that during the Cretaceous geological period dominated by dinosaurs, at some point the "order Oxalidales" consisted of what would have been considered one genus and many species. One of those species was the founder of what we today call the family Cephalotaceae. Because of the difficulty of taxonomically placing families in the Oxalidales and the closely related order Malpighiales owing to a lack of common characters (Stevens 2017a,b) and that these orders and their families arose so 
close to the basal Rosid explosion 110 million years ago (Li et al. 2019), it is likely at that time the plants were herbaceous and did not have complex leaves. As such, the Cephalotus lineage likely did not inherit any specific complicated leaf type. If how it develops its leaves is similar to certain of its relatives, the similarities evolved separately from a similar set of genetic predispositions and environmental challenges.

As we have seen above, it is quite easy for a plant lineage to develop compound leaves from simple leaves. Shifting the balance of the leaf primordia developmental signals in the outer/abaxial direction can result in leaflets piling up on the far abaxial side producing a leaf with a strong rachis containing many leaflets like Juglans (walnut), while shifting the balance in/adaxially produces sided palmate leaves like Acer (maple) and, in the extreme, peltate palmate leaves like Oxalis and Tropaeolum. Cephalotus went in the same direction as Oxalis. Cephalotus most likely went from one to three to five leaflets prior to evolving pitchers. Were the leaflets fused like they can be in Acer and are in Tropaeolum or separate like in Oxalis? At some point they had to fuse to make pitchers but there needs to be an environmental reason to do so. Acer and Tropaeolum do not accumulate water in their leaves. There would be reasons for a Cephalotus ancestor not to accumulate water in its leaves unless it was already carnivorous and the water allowed it to capture more prey.

There is evidence that all other pitcher or pitcher-like carnivorous leaves evolved from sticky carnivorous leaves. Nepenthes closest living relatives are the sticky leaved Drosophyllum and Triphyophyllum. Sarracenia, Heliamphora, and Darlingtonia have Roridula as a close relative; Genlisea and Utricularia have Pinguicula. The advantage of pitchers over sticky leaves is in rainy environments, the rain will wash prey off the sticky leaves and the mucilage that could trap more. The rainforest sundew, Drosera schizandra, in the wild is only a nominal carnivore because of rain (Fleischmann 2011; Fleischmann et al. 2018). In addition, it has the problem of "theft" of prey by ants and other animals (Bourke 2006; McPherson 2008). Cephalotus today lives in an environment where ants are common and specializes in trapping them (Cross et al. 2019). If Cephalotus started out as a sticky-leaved carnivore, there would be an advantage evolutionarily to catch the ants that plague sticky-leaved carnivores in rainy locations. But how can that happen in a step-by-step manner where each step is advantageous in the present?

To the extent that ancestral Cephalotus leaves developed in a way similar to Oxalis with the leaf apexes pointed at the apical meristem, simple shifts in the developmental signaling could easily produce a pitcher-like leaf. First, signaling changes can shift separate leaflets to leaflets fused toward the base. This would be required to construct a pitcher. Second, rather than bending the petiole a full $180^{\circ}$, the plant could have reduced the petiole bend and increased the growth of the most distal leaflet. This would have created a pouch from three leaflets. This developmental shift makes what was the sun side of the leaf, the internal part, while the shade side becomes the outside exposed to the sun. There has to be a very good reason for this shift. It only makes sense if the sun side is the carnivorous surface of the leaf and the plant can trap more prey if the carnivorous side is inside a pitcher.

The development of the Cephalotus pitcher lid is similar to the development of the fourth/inner/adaxial leaflet of $O$. tetraphylla. During development, the fourth leaflet of $O$. tetraphylla faces toward the other three leaflets which face toward it. During Cephalotus evolution, the leaflets that became the lid appear to have fused separately from the other three leaflets. As far as I can find in the literature, this sort of adaxial/abaxial interaction has not been studied so it could be a coincidence with the two species, or a general principle related to leaflets on the inner/adaxial side of the leaf. The lid created by these adaxial leaflets would only be useful if the whole leaf flips $90^{\circ}$ from what was probably the ancestral state. 


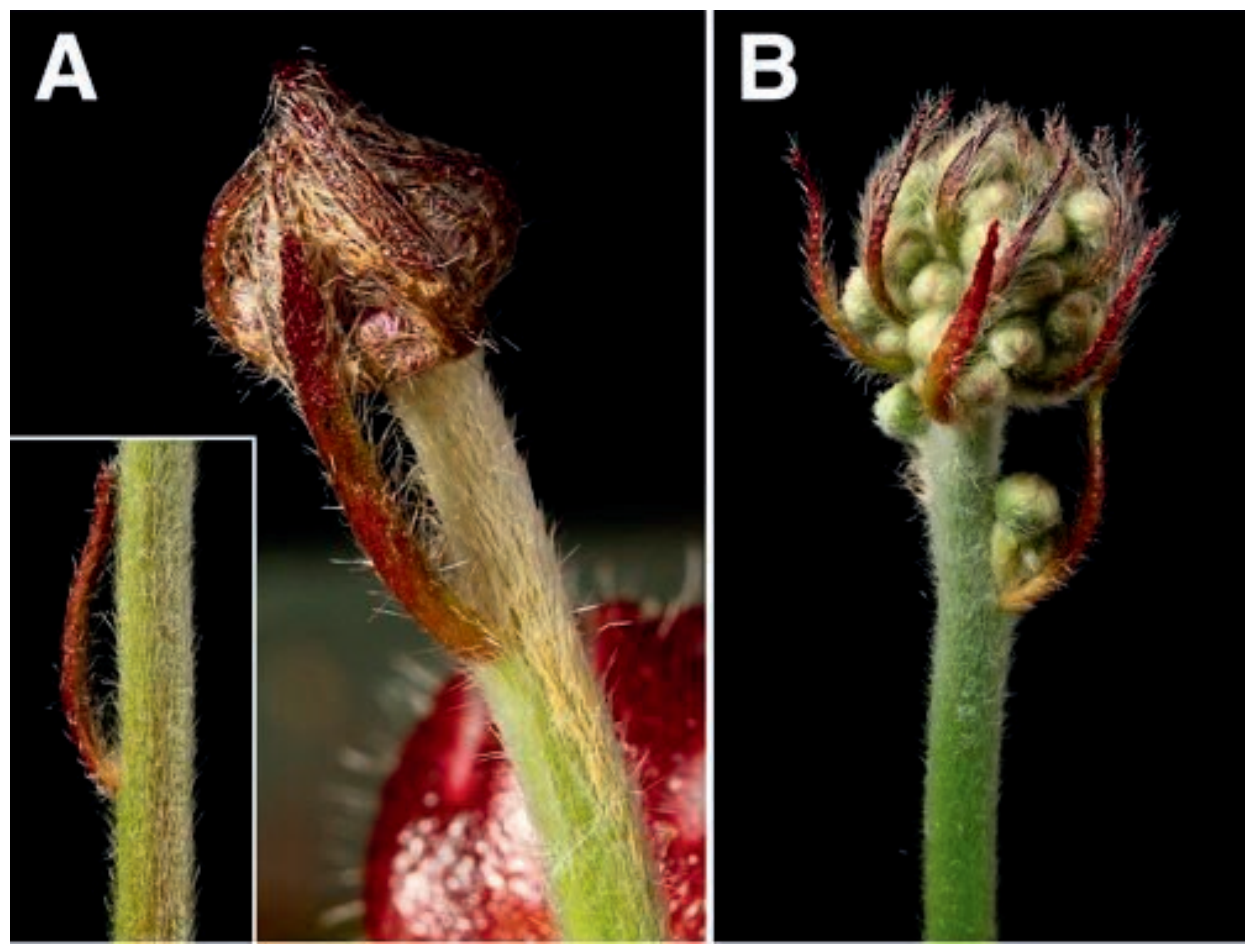

Figure 13: Cephalotus flower scapes. The bracts look suspiciously like pitcher front keels. The scape is a rounded " $D$ " shape in cross section. The inset in $\mathbf{A}$ shows the scape in A 14 days later, after the adaxial face turned red. B is a different scape but same clone.

The most difficult leaf segment to consider evolutionarily is the front keel. It is long and linear unlike the other developmental domains although they show hints of it centrally. The bracts on flower scapes of Cephalotus look suspiciously like the front keel (Fig. 13). In general, bracts are simplified normal leaves and probably use parts of the same genetic program that creates the regular leaves for the plant. Many plants can have bracts on their flower scapes occasionally replaced by incomplete or complete leaves. The bracts on $O$. tetraphylla flower scapes look like the scale-like leaf bases that also make up much of the underground bulb. They do not look like a leaf I observed on an O. tetraphylla flower scape with only one leaflet. That leaf was truncate. In Cephalotus, the bracts on the flower scapes are most likely present to defend against predation. A keel-like leaf would provide the best protection without interfering with flowering.

The pitcher side wings and "teeth" of the mouth are associated with the lateral developmental domains. The teeth appear to be modified leaf-margin hairs. But the wings are curious because they are internal to the developmental domain. Notice in the photo of the Cephalotus seedling in Figure 8 how the lid of this particular plant also shows structures similar to the wings. I like to think that the sticky leaved Cephalotus ancestor had heart-shaped leaflets with hairs on the leaf margins similar to Oxalis. With heart-shaped leaves, the teeth would have evolved from leaf-margin hairs at the broad distal margin of the leaflets. The wings resulted from fused leaf margins in the notch of the heart. Once there are hairs internally to the leaf in a particular area, evolution has something to work with and can enhance it if it is useful. However, there could be something completely different happening 
with the wings. It could simply be an expression of the keel centrally as seen in the intermediate leaf in Figure 9A-B. This could mean an ancestral leaf or the leaflets could have been similar to the bracts and keel.

The pitcher back is the last part of the leaf to complete development. Froebe and Baur (1988) imagined an ancestral leaf for Cephalotus with a strong rachis similar to Vesselowskya venusta, an Australian member of Oxalidales family Cunoniaceae (cf. image in Wikipedia), except their drawing shows the two most proximal leaflets fused adaxially. The back of the Cephalotus pitcher is analogous to a rachis in the sense that the back spreads the fused leaflet domains in the way a rachis separates entire leaflets. But that does not mean the Cephalotus pitcher back is homologous to a rachis in an evolutionary sense. It is extremely unlikely the common ancestor of the Oxalidales was sufficiently specialized to have a rachis. An ancestor in the Cephalotus lineage would also be unlikely to have a strong rachis. It would be difficult evolutionarily to get from a leaf as specialized as is the leaf of V. venusta, or even O. tetraphylla, to a Cephalotus pitcher. Irrespective of the history, a concept of what happens with a rachis is occurring late in the development of Cephalotus pitchers.

Even if we had a complete understanding of Cephalotus leaves, it would not be possible to draw pictures of the ancestral leaves with any confidence. We would know what had to happen over the past 80 million years, but we would not know the sequence of events. At various points there would have had to be one, three, then five leaflets or leaflet developmental domains. At some point before the leaves started to evolve into a pitcher, the plant was most likely carnivorous. At some point three of the carnivorous leaflets had to fuse in order to hold water while the other two fused to create a lid. At some point the leaves became peltate. However, without knowing the sequence of details, we can see how what at first glance is a bizarre leaf, actually results from simple developmental shifts with added ornamentation. Given the millions of years of evolutionary time, the curious ornamentation of prey guides, teeth on the trap margins, and light windows are details that had plenty of time to evolve into their current form.

Acknowledgements: I thank Andreas Fleischmann and Vera Gottlieb for helpful discussion. Robert Gibson, John Conran, and Jan Schlauer provided useful comments on the manuscript.

\section{References}

Arber, A. 1941. On the morphology of the pitcher-leaves in Heliamphora, Sarracenia, Darlingtonia, Cephalotus, and Nepenthes. Annals of Botany 5(20): 563-578.

Bharathan, G., Goliber, T.E., Moore, C., Kessler, S., Pham, T., and Sinha, N.R. 2002. Homologies in leaf form inferred from KNOXI gene expression during development. Science 296: 1858-1860. Bourke, G. 2006. Searching for the three sisters. Carniflora Australis 7: 24-30.

Champagne, C.E., Goliber, T.E., Wojciechowski, M.F., Mei, R.W., Townsley, B.T., Wang, K., Paz,

M.M., Geeta, R., and Sinha, N.R. 2007. Compound leaf development and evolution in the legumes. Plant Cell 19(11): 3369-3378.

Clayton, C.H. 2013. Cephalotus follicularis 'Clayton's T Rex'. Carniv. Pl. Newslett. 42(4): 145.

Cross, A., Kalfas, N., Nunn, R., and Conran, J. 2019. Cephalotus - the Albany Pitcher Plant. Redfern

Natural History Productions, Poole, Dorset, England.

DeGreef, J.D. 1990. Cephalotus follicularis: history and evolution. Carniv. P1. Newslett. 19(3-4): 95-103.

Dickson, A. 1883. On the morphology of the pitcher of Cephalotus follicularis. Trans. Bot. Soc. Edinburgh 14(1-4): 172-181. 
Efroni, I., Yuval. E., and Lifschitz, E. 2010. Morphogenesis of simple and compound leaves: a critical review. Plant Cell 22(4): 1019-1032.

Evans, J.R., and Vogelmann, T.C. 2006. Photosynthesis within isobilateral Eucalyptus pauciflora leaves. New Phytol. 171(4): 771-782.

Fleischmann, A. 2011. Do we have any evidence that any plants have given up carnivory? Carniv. P1. Newslett. 40(1): 37.

Fleischmann, A., Schlauer, J., Smith, S.A., and Givnish, T.J. 2018. Evolution of carnivory in angiosperms. In: Ellison, A.M., and Adamec, L. (eds.). Carnivorous Plants: Physiology, Ecology, and Evolution. Oxford University Press, Oxford, U.K., pp. 22-41.

Franck, D.H. 1976. The morphological interpretation of epiascidiate leaves. An historical perspective. Bot. Rev. 42(3): 345-388.

Froebe, H.A., and Baur, N. 1988. Die Morphogenese der Kannenblätter von Cephalotus follicularis Labill. Akademie Der Wissenschaften und der Literatur. Abhandlungen der MathematischNaturwissenschaftlichen Klasse 3: 1-19.

Fukushima, K., Fujita, H., Yamaguchi, T., Kawaguchi, M., Tsukaya, H., and Hasebe, M. 2015. Oriented cell division shapes carnivorous pitcher leaves of Sarracenia purpurea. Nat. Commun. 6:6450 doi: 10.1038/ncomms7450.

Fukushima, K., and Hasbe, M. 2014. Adaxial-abaxial polarity: the developmental basis of leaf shape diversity. Genesis 52(1): 1-18.

Hagemann, W., and Gleissberg, S. 1996. Organogenetic capacity of leaves: the significance of marginal blastozones in angiosperms. Pl. Syst. Evol. 199: 121-152.

Heibl, C., and Renner, S.S. 2012. Distribution models and a dated phylogeny for Chilean Oxalis species reveal occupation of new habitats by different lineages, not rapid adaptive radiation. Syst. Biol. 61(5): 823-834.

Li, H.-T., Yi, T.-S., Gao, L.-M., Ma, P.-F., Zhang, T., Yang, J.-B., Gitzendanner, M., Fritsch, P., Cai, J., Luo, Y., Wang, H., van der Bank, M., Zhang, S.-D., Wang, Q.-F., Wang, J., Zhang, Z.-R., Fu, C.-N., Yang, J., Hollingsworth, P., Chase, M., Soltis, D., Soltis, P., and Li, D.-Z. 2019. Origin of angiosperms and the puzzle of the Jurassic gap. Nat. Plants 5(5): 461-470.

Lloyd, F.E. 1942. The Carnivorous Plants. Chronica Botanica, Waltham, MA.

Macfarlane, J.M. 1889. Observations on pitchered insectivorous plants. (Part I.) Ann. Bot. 3(10): 253-266.

McPherson, S. 2008. Glistening Carnivores. Redfern Natural History Productions, Poole, Dorset, England.

Nunn, R. 2014 New insights into the growth cycle of Cephalotus follicularis. Carniv. Pl. Newslett. 43(3): 93-96.

Stevens, P.F. 2017a. Oxalidales. In: Angiosperm Phylogeny Website. Version 14, July 2017. http:// www.mobot.org/mobot/research/apweb/orders/oxalidalesweb.htm.

Stevens, P.F. 2017b. Malpighiales. In: Angiosperm Phylogeny Website. Version 14, July 2017. http:// www.mobot.org/mobot/research/apweb/orders/malpighialesweb.htm.

Waites, R., and Hudson, A. 1995. Phantastica: a gene required for dorsoventrality of leaves in Antirrhinum majus. Development 121(7): 2143-2154.

Yamaguchi, T., Nukazuka, A., and Tsukaya, H. 2012. Leaf adaxial-abaxial polarity specification and lamina outgrowth: evolution and development. Pl. Cell Physiol. 53(7): 1180-1194. 


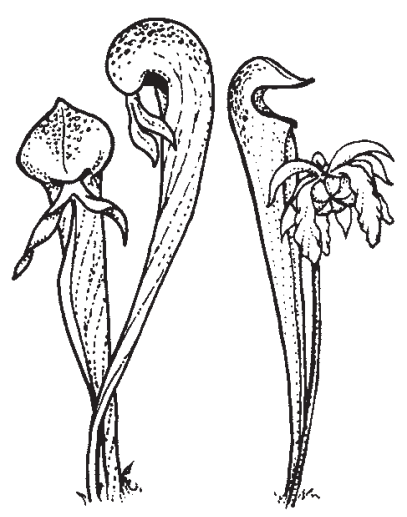

\section{CARNIVOROUS \\ PLANT \\ NEWSLETTER}

Journal of the International

Carnivorous Plant Society

www.carnivorousplants.org

Volume 49, Number 3 September 2020

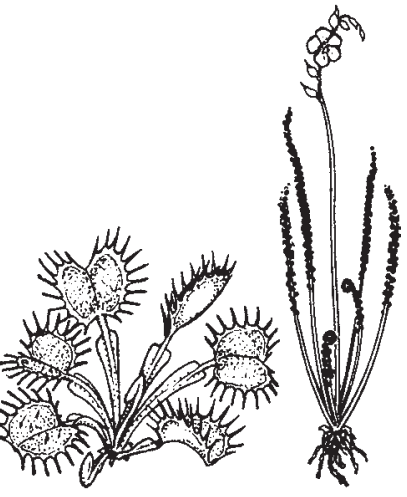

Front Cover: The cultivar Heliamphora 'Cyclops'. Photo by Andy Smith. Article on page 141.

Back Cover: The cultivar Cephalotus ‘OG Black' pitchers. Photo by John Brittnacher. Article on page 103.

Carnivorous Plant Newsletter is dedicated to spreading knowledge and news related to carnivorous plants. Reader contributions are essential for this mission to be successful. Do not hesitate to contact the editors with information about your plants, conservation projects, field trips, or noteworthy events. Advertisers should contact the editors. Views expressed in this publication are those of the authors, not the editorial staff.

All correspondence regarding dues, address changes and missing issues should be sent to the Membership Coordinator at the ICPS. Do not send such correspondence to the editors. Checks for subscriptions should be made to the International Carnivorous Plant Society in US funds. Dues, including a subscription, are \$30 per year.

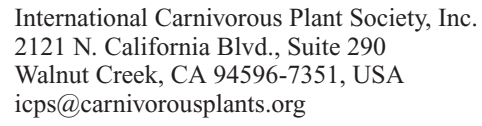

President

Vice President

Secretary

Treasurer

Board Member

Board Member

Board Member

Board Member

Membership Coordinator

Webmaster

Media Coordinator

Seed Bank Manager

CPN Editors

Managing Editor

Editor

Editor

Editor

Science Editor

Science Editor

Science Editor

\author{
Richard Nunn, richardnunn@carnivorousplants.org \\ John Brittnacher, john@carnivorousplants.org \\ Cindy Slezak, cindy@carnivorousplants.org \\ Daniela Ribbecke, daniela@carnivorousplants.org \\ Brent Jones, Conservation Director, brent@carnivorousplants.org \\ Kenny Coogan, Education Director, kenny@carnivorousplants.org \\ Jan Schlauer, Cultivar Registrar, jan@carnivorousplants.org \\ Bob Ziemer, bob@carnivorousplants.org \\ Cindy Slezak, cindy@carnivorousplants.org \\ John Brittnacher, john@carnivorousplants.org \\ ChadWilliams, chad@carnivorousplants.org \\ Joe Griffin, joe@carnivorousplants.org \\ editor@carnivorousplants.org \\ Bob Ziemer \\ Barry Rice \\ Karl Herold \\ John Brittnacher \\ Andreas Fleischmann \\ Fernando Rivadavia \\ Jan Schlauer
}

Date of effective publication of the June 2020 issue of Carnivorous Plant Newsletter: May 15, 2020.

The ICPS is the International Cultivar Registration Authority (ICRA) for the names of cultivated carnivorous plants according to the International Code of Nomenclature for Cultivated Plants. Send relevant correspondence to the ICPS, Inc.

Carnivorous Plant Newsletter is published quarterly in March, June, September, and December by the ICPS, Inc., 2121 N. California Blvd., Suite 290, Walnut Creek, CA 94596, USA. Periodicals postage paid at Walnut Creek, CA and additional mailing offices. Postmaster: Send address changes to ICPS, Inc., 2121 N. California Blvd., Suite 290, Walnut Creek, CA 94596, USA. Printed by Allen Press, Inc., 810 E. 10th Street, Lawrence, KS 66044. Logo and masthead art: Paul Milauskas. (C) 2020 International Carnivorous Plant Society. All rights reserved. ISSN \#0190-9215 